\title{
Regulação da Ingestão Protéica na Tilápia do Nilo, Oreochromis niloticus ${ }^{1}$
}

\section{Elyara Maria Pereira-da-Silva², Débora Niero Orsoli ${ }^{3}$, Lúcio Francelino Araújo ${ }^{4}$, Osmar Ângelo Cantelmo $^{5}$, Giovana Krempel Fonseca Merighe ${ }^{6}$}

\begin{abstract}
RESUMO - Estudou-se a habilidade de juvenis de tilápia do Nilo, Oreochromis niloticus, em regular a ingestão protéica. Mil exemplares com peso e comprimento de 13,93g $\pm 0,87 \mathrm{~g}$ e $8,8 \mathrm{~cm} \pm 0,47 \mathrm{~cm}$, respectivamente, revertidos sexualmente, foram distríbuídos em oito grupos de 125 peixes, em aquários de 1.000 L com renovação contínua de água e dotados de dois alimentadores de demanda. Duas rações isoenergéticas ( $2.800 \mathrm{kcal} / \mathrm{kg}$ ) contendo, respectivamente, $40 \%$ e $15 \%$ PB foram oferecidas diariamente, ad libitum, em combinações que caracterizaram quatro tratamentos: A: ração de 15\% PB de um lado e de 40\% PB do outro do aquário; B: idêntico ao tratamento A com inversão dos lados; C: ração de $15 \%$ PB fornecida em dois alimentadores; e D: ração de 40\% PB fornecida em dois alimentadores. O delineamento em quadrado latino permitiu que os peixes fossem submetidos a cada tratamento durante quatro fases de 15 dias (I, II, III e IV). Entre as fases, houve intervalo de uma semana, quando os peixes receberam dieta contendo $30 \% \mathrm{~PB}$ nos dois alimentadores. O consumo alimentar dos peixes, registrado diariamente, não diferiu significativamente entre os tratamentos A e B. Porém, quando foram apresentadas simultaneamente as dietas contendo mesmo teor de PB (Tratamentos C e D), observou-se consumo significativamente maior da ração contendo 15\% de PB (Tratamento C). O ajuste em porcentagem da proteína ingerida pelos peixes revelou média de 24\% de PB. Os resultados confirmaram a hipótese de que a tilápia do Nilo apresenta habilidade em regular a ingestão dietética protéica por meio de livre escolha.
\end{abstract}

Palavras-chave: comportamento alimentar, livre escolha, Oreochromis niloticus, proteína, tilápia do Nilo

\section{Hability of Protein Intake Regulation in Nile Tilapia, Oreochromis niloticus}

\begin{abstract}
The free-choice feed and regulation of protein intake were investigated in juveniles reverted males of tilápia do Nilo, Oreochromis niloticus. During the experiment 1000 fish (reverted males) with similar weigth and length were maintained in eight aquariuns supplied with recirculated water (groups of 125 fish each aquarium). Fish were fed by demand-feeders, containing the two experimental diets, formulated to contain $15 \%$ and $40 \%$ protein each and distributed in four treatments (A: $15 \%$ protein diet on one hand and $40 \%$ protein diet on the other hand, B: alike in A, therefore with an inversion on both hands, C: the two feeders supplied with $15 \%$ protein diet, D the two feeders supplied with $40 \%$ protein diet) The Latin Square was the estatistical method used for the experiment, and the treatments were distributed into four stages (I, II, III and IV). A one week stop after each stage was stipulated and the fish received a $30 \%$ protein diet. The results showed that no differences about the intake was detected between fish fed by diets containing $15 \%$ and $40 \%$ protein in the same aquarium. However, with same diets in the tanks ( Treatment $C$ and D), the animals that were fed with the $15 \%$ protein diet showed better feed intake. The percentage of regulated protein during the experiment was about $24 \%$ protein. The results confirm the hipoteses of free-choice ability by tilápia-do-Nilo to detect the level of protein in the diet.
\end{abstract}

Key Words: feed behaviour, free choice, Nile Tilápia, Oreochromis niloticus, protein

\section{Introdução}

Muitas formas e composições de dietas para peixes têm sido elaboradas, mas são poucos os estudos que correlacionam os mecanismos de digestão e as exigências das diferentes espécies a seus comportamentos alimentares e sociais, havendo ainda a busca pelo manejo ideal e pela determinação do alimento melhor e economicamente mais viável.
Segundo Tacon (1989), muitos trabalhos são realizados com o intuito de determinar a necessidade de proteína, porém não há um consenso, o que pode ser decorrente da falta de padronização experimental. Esta padronização do conteúdo protéico das dietas artificiais para peixes seria ideal não somente do ponto de vista econômico, posto que a proteína representa o item mais caro da dieta (Hepher, 1988), como também em função das questões ambientais

\footnotetext{
${ }^{1}$ Dissertação de Mestrado da segunda autora (Bolsista CAPES).

2 Docente Depto Ciências Básicas FZEA/USP - Pirassununga - SP/Brasil (elyara@usp.br).

3 Bióloga, Mestre em Zootecnia (Qualidade e Produtividade Animal) FZEA/USP (dnmansi@esalq.usp.br).

${ }^{4}$ Docente Depto Zootecnia FZEA/USP - Pirassununga - SP/Brasil (Ifaraujo@usp.br).

5 Pesquisador Doutor - CEPTA/IBAMA - Pirassununga - SP/Brasil (cantelmo@cepta.ibama.gov.br).

${ }^{6}$ Biomédica, Mestre em Zootecnia, Especialista em Laboratório - FZEA/USP (gkrempel@usp.br).
} 
relacionadas ao potencial poluente das rações (Kubitza, 1999, 2000).

De acordo com Forbes (1995), os animais são sensíveis a um grande número de nutrientes e podem fazer escolhas apropriadas, mas os limites de suas habilidades em escolher entre dois ou mais nutrientes simultaneamente não estão claramente estabelecidos.

São muitos os benefícios decorrentes da livre escolha, que se caracteriza como o sistema mais natural e delicado de alimentação e, assim, muitas pesquisas têm sido realizadas com aves, suínos e bovinos, visando o estudo do controle da ingestão de nutrientes, como a proteína, por meio da opção entre duas ou mais dietas. Para peixes, os trabalhos encontrados enfocam a utilização e a influência de diferentes níveis de proteína sobre o desempenho, não havendo referências sobre a habilidade de escolha entre dietas.

Referências específicas sobre a habilidade de livre escolha são escassas, podendo-se citar os trabalhos de Boujard \& Médalé (1994), que estudaram a capacidade da truta arco-íris (Oncorhynchus mykiss) em regular a ingestão de alimento, em função de seu conteúdo energético.

Kentouri et al. (1995) pesquisaram o comportamento alimentar de Sparus aurata, utilizando três rações com diferentes balanceamentos, e concluíram que esses peixes têm capacidade de regular a ingestão com base nos teores de proteína e de energia da dieta, além de escolher a quantidade de cada dieta para atender suas necessidades nutricionais. Cantelmo et al. (1998) demonstraram a capacidade de regulação da ingestão dietética por meio do nível protéico da dieta, em matrinchãs (Brycon cephalus.)

Seria ideal, em termos nutricionais e econômicos, que as dietas práticas para os peixes fossem estabelecidas em função de experimentos em que os próprios peixes regulassem o momento, o alimento e sua quantidade ingerida. Portanto, objetivou-se, com este trabalho, verificar a habilidade de livre escolha entre dietas com diferentes níveis de proteína e definir a quantidade de proteína dietética ingerida pela tilápia do Nilo na fase de recria.

\section{Material e Métodos}

Foram utilizados mil exemplares de juvenis de tilápia do Nilo (Oreochromis niloticus), com pesos e comprimentos de $13,93 \mathrm{~g} \pm 0,87 \mathrm{~g}$ e $8,8 \mathrm{~cm} \pm 0,47 \mathrm{~cm}$, respectivamente, revertidos sexualmente.

Os peixes foram divididos em oito grupos de 125 animais e transferidos aleatoriamente para oito aquários de $1000 \mathrm{~L}$ (unidades experimentais circulares confeccionadas em fibra de vidro), providos de dois alimentadores de demanda (confeccionados artesanalmente utilizando-se garrafas, PET) e de sistema de renovação contínua de água (proveniente de represa), com fluxo constante e renovação total a cada 60 minutos.

Os animais permaneceram nessas condições durante 15 dias, para adaptação à dieta, fornecida em alimentadores de demanda, abastecidos diariamente com a ração contendo $30 \%$ de $\mathrm{PB}$.

Foram elaboradas duas rações peletizadas contendo, respectivamente, 15 e $40 \%$ de PB com 2.800 kcal de energia digestível. A composição das rações e seus níveis nutricionais são apresentados nas Tabelas 1 e 2, respectivamente.

Após a aclimatação dos peixes, foram estabelecidos os tratamentos, que consistiram no oferecimento de duas rações (15\% e 40\% PB) em diferentes combi-

Tabela 1 - Composição química calculada das dietas experimentais

Table 1 - Chemical composition of the experimental diets

\begin{tabular}{|c|c|c|}
\hline \multirow[t]{2}{*}{$\begin{array}{l}\text { Ingredientes (\%) } \\
\text { Ingredient }\end{array}$} & \multicolumn{2}{|c|}{$\begin{array}{l}\text { Dietas } \\
\text { Diets }\end{array}$} \\
\hline & $15 \%$ & $40 \%$ \\
\hline $\begin{array}{l}\text { Milho moído } \\
\text { Corn }\end{array}$ & 59,70 & 14,95 \\
\hline $\begin{array}{l}\text { Farelo de trigo } \\
\text { Wheat meal }\end{array}$ & 25,00 & - \\
\hline $\begin{array}{l}\text { Farelo de soja } \\
\text { Soybean meal }\end{array}$ & 8,00 & 55,00 \\
\hline $\begin{array}{l}\text { Farinha de peixe } \\
\text { Fish meal }\end{array}$ & 4,00 & 24,50 \\
\hline $\begin{array}{l}\text { Fosfato bicálcico } \\
\text { Dicalcium phosphate }\end{array}$ & 2,50 & - \\
\hline $\begin{array}{l}\text { L-lisina } \\
\text { L-Lysine }\end{array}$ & 0,250 & - \\
\hline $\begin{array}{l}\text { Óleo de soja } \\
\text { Soybean oil }\end{array}$ & - & 5,00 \\
\hline $\begin{array}{l}\text { Sal comum } \\
\text { Salt }\end{array}$ & 0,05 & 0,05 \\
\hline $\begin{array}{l}\text { Premix vitamínico/mineral } \\
\text { Vitamin/mineral mix }\end{array}$ & 0,50 & 0,50 \\
\hline Total & 100,00 & 100,00 \\
\hline
\end{tabular}

$\mathrm{kg}$ de premix vitamínico/mineral ( $\mathrm{kg}$ vitamin/mineral mix): Vit.A 600.000 UI; Vit. $D_{3}$ - 100.000 UI; Vit. E - 6.000; Vit C - 50 g; Tiamina (Thiamin) - 2,4 g; Riboflavina (Riboflavin) - 2,4 g; Ac. pantotênico (Pantothenic acid) - 6,0 g; Niacina (Niacin) - 12 g; Piridoxina (Piridoxin) - 2,4 g; Biotina (Biotin) - 24 mg; Ac. fólico (Folic acid) - 600 mg; Colina (Choline) - $55 \mathrm{~g}$; Vit.B 12 2,4 mg; Antioxidante (Antioxidant) - $5 \mathrm{~g}$; $\mathrm{Fe}-5 \mathrm{~g} ; \mathrm{Cu}$ - 0,3 g; Mn - 3 g; Zn - 3 g; I - 10 mg; Co - 1 mg; Se - 10 mg. 
Tabela 2 - Composição química das dietas experimentais

Table 2 - Chemical composition of the experimental diets

\begin{tabular}{lcc}
\hline $\begin{array}{l}\text { Nutrientes } \\
\text { Nutrients }\end{array}$ & \multicolumn{2}{c}{ Nível protéico } \\
& $15 \%$ & $40 \%$ \\
\cline { 2 - 3 } & 15,00 & 40,00 \\
\hline $\begin{array}{l}\text { Proteína bruta (\%) } \\
\text { Crude protein }\end{array}$ & 4,50 & 3,70 \\
$\begin{array}{l}\text { Fibra bruta (\%) } \\
\text { Crude fiber }\end{array}$ & 2.800 & 2.800 \\
$\begin{array}{l}\text { Energia digestível (kcal/kg) } \\
\text { Digestible energy }\end{array}$ & 0,80 & 0,80 \\
$\begin{array}{l}\text { Fósforo (\%) } \\
\text { Phosphorus }\end{array}$ & 1,00 & 2,10 \\
$\begin{array}{l}\text { Cálcio (\%) } \\
\text { Calcium } \\
\text { Metionina + cistina (\%) }\end{array}$ & 0,60 & 1,33 \\
$\begin{array}{l}\text { Methionine + cystine } \\
\text { Lisina (\%) }\end{array}$ & 0,93 & 2,40 \\
\begin{tabular}{l} 
Lysine \\
\hline
\end{tabular} & & \\
\hline
\end{tabular}

nações, que caracterizaram quatro tratamentos: $A$, B, C e D, distribuídos em quatro fases (15 dias cada).

Tratamento A: alimentadores com ração de 15\% de $\mathrm{PB}$ de um lado e de $40 \%$ de $\mathrm{PB}$ do outro; Tratamento B: semelhante ao tratamento A, porém com inversão da posição dos alimentadores; tratamento C: dois alimentadores abastecidos com ração de 15\% PB; tratamento D: dois alimentadores abastecidos com ração de $40 \% \mathrm{~PB}$.

Foi utilizado o delineamento em quadrado latino, com quatro tratamentos (A, B, C e D), quatro fases, e oito repetições, sendo cada grupo de 125 animais por aquário (unidade experimental).

Visando minimizar possíveis efeitos de uma fase sobre a outra, foi estabelecido intervalo de uma semana entre cada uma das fases, oferecendo-se aos peixes dietas contendo $30 \%$ de $\mathrm{PB}$, simultaneamente, nos dois alimentadores de demanda.

Os tratamentos A e B diferiram apenas quanto ao posicionamento dos alimentadores (lados invertidos), com o objetivo de evitar que os peixes pudessem se orientar por qualquer ponto de referência como a fonte de luz do laboratório ou a entrada d'água dos aquários.

Os alimentadores foram reabastecidos diariamente (12h), registrando-se o consumo por meio da diferença dos pesos inicial e final da ração em um período de 24 horas. Para análise, utilizaram-se valores de consumo semanais e quinzenais acumulados.
Os restos de fezes e/ou de alimentos foram carreados continuamente pelo sistema caracterizado como auto-limpante e com drenagem central e, a cada três semanas, quando os animais foram removidos para pesagem, foi realizada a limpeza dos aquários.

Foram registrados diariamente as temperaturas da água e, semanalmente, os valores de $\mathrm{pH}$ e as concentrações de amônia, de nitrito e de oxigênio dissolvido.

Para avaliação do crescimento, a cada três semanas todos os peixes foram pesados (biomassas totais de cada unidade experimental) e 50 indivíduos de cada aquário foram medidos (comprimento total).

Os valores médios do consumo de alimento foram submetidos à análise de variância (Steel et al., 1997) e, quando significativo $(\mathrm{p}<0,05)$, as médias foram comparadas pelo o teste Tukey.

Com base nos dados de consumo alimentar registrados para os tratamentos $\mathrm{A}$ e $\mathrm{B}$, nas quatro fases experimentais e ao final do experimento (valor médio acumulado), calculou-se, por regra de três, a porcentagem de proteína efetivamente ingerida pelos peixes. Não foram realizados os cálculos para os tratamentos $\mathrm{C}$ e $\mathrm{D}$, nos quais peixes não tiveram a possibilidade de escolha.

Exemplo de esquema de cálculo do tratamento A (15\% e $40 \%$ PB):

Valor total de ração consumida no aquário $=100$

Valor da ração consumida no alimentador 1 (15\% de $\mathrm{PB})=\mathbf{X}$

X x 0,15 $(15 \%$ PB $)=$ porcentagem de proteína ingerida no alimentador 1 (P1)

Valor total de ração consumida no aquário $=100$

Valor de ração consumida no alimentador 2 (40\% de $P B)=\mathbf{Y}$

Y x 0,40 $(40 \%$ PB $)=$ porcentagem de proteína ingerida no alimentador 2 (P2)

$\mathbf{P 1}+\mathbf{P 2}=$ porcentagem de proteína ingerida no aquário

O cálculo foi realizado durante todas as fases e, para o resultado final, utilizou-se a média de cada fase e a soma destas, obtendo-se o valor total final.

\section{Resultados e Discussão}

Os valores registrados para os parâmetros indicadores da qualidade da água ( Tabela 3) encontramse dentro da faixa de conforto da espécie, de acordo com Vinatca (1997) e Kubitza (2000).

Quanto ao consumo médio semanal de alimento (Tabela 4), os animais comportaram de modo seme- 
lhante quando submetidos aos tratamentos A e B, sugerindo que não houve efeito da posição dos alimentadores e que os peixes foram capazes de reconhecer as diferentes dietas. Em ambos os tratamentos (A e B), houve maior consumo da ração de $15 \%$ PB, mesmo com a inversão dos alimentadores.

As respostas dos peixes, estabelecidas já na primeira semana de tratamento, foram semelhantes entre a primeira e segunda semanas de cada fase experimental. Apesar de o consumo da dieta contendo 15\% de PB ter sido significativamente superior $(\mathrm{p}<0,05)$ em todos os tratamentos, não houve diferença significati- va do consumo entre os dois alimentadores contendo rações de mesmo nível protéico, ou seja, presentes num mesmo tratamento (C ou D).

As mesmas respostas foram observadas quanto ao consumo médio de alimento verificado quinzenalmente (Tabela 5).

Não houve diferença significativa $(\mathrm{p}>0,05)$ entre os tratamentos A (15\% e $40 \%$ de $\mathrm{PB})$ e B ( $40 \%$ e $15 \%$ de $\mathrm{PB}$ ), mas o consumo dos animais submetidos ao tratamento C (15\% e $15 \%$ de $\mathrm{PB}$ ) foi significativamente superior $(\mathrm{p}<0,05)$ ao dos animais do tratamento D ( $40 \%$ e $40 \%$ de $\mathrm{PB})$.

Tabela 3 - Parâmetros indicadores da qualidade da água Table 3 - Water quality indicators parameters

\begin{tabular}{lccccc}
\hline $\begin{array}{l}\text { Tratamento } \\
\text { Treatment }\end{array}$ & $\begin{array}{c}\text { Oxigênio }(\mathrm{mg} / \mathrm{L}) \\
\text { Oxygen }\end{array}$ & $\begin{array}{c}\text { Temperatura }\left({ }^{\circ} \mathrm{C}\right) \\
\text { Temperature }\end{array}$ & $\begin{array}{c}\text { Amônia }(\mathrm{mg} / \mathrm{L}) \\
\text { Ammonia }\end{array}$ & $\begin{array}{c}\text { Nitrito }(\mathrm{mg} / \mathrm{L}) \\
\text { Nitrite }\end{array}$ & $\begin{array}{c}\mathrm{pH} \\
\mathrm{pH}\end{array}$ \\
\hline A & $4,08 \pm 0,95$ & $27,0 \pm 0,02$ & $0,46 \pm 0,17$ & $0,007 \pm 0,00$ & $6,47 \pm 0,09$ \\
B & $4,11 \pm 0,92$ & $27,0 \pm 0,02$ & $0,46 \pm 0,18$ & $0,007 \pm 0,00$ & $6,44 \pm 0,10$ \\
C & $4,69 \pm 0,83$ & $27,0 \pm 0,02$ & $0,46 \pm 0,17$ & $0,007 \pm 0,00$ & $6,42 \pm 0,08$ \\
D & $4,49 \pm 0,61$ & $27,0 \pm 0,02$ & $0,47 \pm 0,17$ & $0,007 \pm 0,00$ & $6,45 \pm 0,09$ \\
\hline
\end{tabular}

$A=$ um alimentador com ração $15 \%$ de $\mathrm{PB}$ e outro com ração $40 \%$ de $\mathrm{PB}$.

$B=$ semelhante ao tratamento $A$, porém com inversão dos lados.

$\mathrm{C}=$ dois alimentadores abastecidos com rações 15\% de PB.

$\mathrm{D}=$ dois alimentadores abastecidos com rações $40 \%$ de $\mathrm{PB}$.

$A=15 \%$ protein diet on one hand and $40 \%$ protein diet on the other hand.

$B=$ alike in $A$, therefore with an inversion on both hands.

$C=$ two feeders supplied with $15 \%$ protein diet.

$D=$ two feeders supplied with $40 \%$ protein diet.

Tabela 4 - Consumo médio (g) de alimento durante a primeira e segunda semanas de cada fase do experimento Table 4 - Feed intake means $(g)$ in first and second weeks of each experimental phase

\begin{tabular}{lccccc}
\hline $\begin{array}{l}\text { Semanas } \\
\text { Weeks }\end{array}$ & $\begin{array}{c}\text { Alimentador } \\
\text { Feeders }\end{array}$ & \multicolumn{4}{c}{$\begin{array}{c}\text { Tratamentos } \\
\text { Treatments }\end{array}$} \\
\cline { 3 - 6 } & & $\mathrm{A}$ & $\mathrm{B}$ & $\mathrm{C}$ & $\mathrm{D}$ \\
\hline 1 & $\mathrm{I}$ & $1328,1 \mathrm{a}^{1}$ & $683,8 \mathrm{~b}^{2}$ & $1101,3 \mathrm{ab}^{1}$ & $786,9 \mathrm{ab}^{2}$ \\
1 & II & $696,9 \mathrm{a}^{2}$ & $1193,8 \mathrm{~b}^{1}$ & $1203,1 \mathrm{~b}^{1}$ & $568,1 \mathrm{a}^{2}$ \\
2 & $\mathrm{I}$ & $1393,8 \mathrm{a}^{1}$ & $799,4 \mathrm{~b}^{2}$ & $1393,8 \mathrm{a}^{1}$ & $859,4 \mathrm{~b}^{2}$ \\
2 & II & $909,4 \mathrm{a}^{2}$ & $1568,8 \mathrm{~b}^{1}$ & $1399,4 \mathrm{ab}^{1}$ & $965,6 \mathrm{a}^{2}$ \\
\hline
\end{tabular}

$\mathrm{A}=$ um alimentador com ração $15 \%$ de $\mathrm{PB}$ e outro com ração $40 \%$ de $\mathrm{PB}$.

$B=$ semelhante ao tratamento $A$, porém com inversão dos lados.

$\mathrm{C}=$ dois alimentadores abastecidos com rações 15\% de $\mathrm{PB}$.

$\mathrm{D}=$ dois alimentadores abastecidos com rações $40 \%$ de PB.

(1) Consumo de ração contendo $15 \%$ de PB.

(2) Consumo de ração contendo $40 \%$ de PB.

Valores na mesma linha seguidos de letras diferentes diferem significativamente pelo teste Tukey $(P<0,05)$.

$A=15 \%$ protein diet on one hand and $40 \%$ protein diet on the other hand.

$B=$ alike in $A$, therefore with an inversion on both hands.

$C=$ two feeders supplied with $15 \%$ protein diet.

$D=$ two feeders supplied with $40 \%$ protein diet.

(1) Feed intake with $15 \% \mathrm{CP}$.

(2) Feed intake with $40 \% C P$.

Values in the the line followed by different letters differ $(P<.05)$ by Tukey test.

R. Bras. Zootec., v.33, n.6, p.1921-1927, 2004 (Supl. 2) 
Tabela 5 - Consumo total das rações $(\mathrm{g})$ nas quatro fases experimentais Table 5 - Mean feed intake $(g)$ of different experimental phases

\begin{tabular}{lcccc}
\hline $\begin{array}{l}\text { Alimentador } \\
\text { Feeder }\end{array}$ & \multicolumn{4}{c}{$\begin{array}{c}\text { Tratamentos } \\
\text { Treatments }\end{array}$} \\
\cline { 2 - 5 } & $\mathrm{A}$ & $\mathrm{B}$ & $\mathrm{C}$ & $\mathrm{D}$ \\
\hline $\mathrm{I}(15 \% \mathrm{~PB})$ & $2721,9 \mathrm{a}^{1}$ & $1483,1 \mathrm{c}^{2}$ & $2495 \mathrm{ab}^{1}$ & $1646,3 \mathrm{bc}^{2}$ \\
$\mathrm{II}(40 \% \mathrm{~PB})$ & $1606,3 \mathrm{~b}^{2}$ & $2762,5 \mathrm{a}^{1}$ & $2602,5 \mathrm{a}^{1}$ & $1533,8 \mathrm{~b}^{2}$ \\
\hline
\end{tabular}

$A=$ um alimentador com ração 15\% PB e outro com ração 40\% PB.

$B=$ semelhante ao tratamento $A$, porém com inversão dos lados.

$\mathrm{C}=$ dois alimentadores abastecidos com rações $15 \% \mathrm{~PB}$.

$\mathrm{D}=$ dois alimentadores abastecidos com rações 40\% $\mathrm{PB}$.

(1) Consumo de ração contendo $15 \%$ de PB.

(2) Consumo de ração contendo $40 \%$ de PB.

Valores na mesma linha seguidos de letras diferentes diferem significativamente pelo teste Tukey $(P<0,05)$.

$A=15 \%$ protein diet on one hand and $40 \%$ protein diet on the other hand.

$B=$ alike in $A$, therefore with an inversion on both hands.

$C=$ two feeders supplied with $15 \%$ protein diet.

$D=$ two feeders supplied with $40 \%$ protein diet.

(1) Feed intake with 15\% CP.

(2) Feed intake with $40 \% \mathrm{CP}$

Values in the the line followed by different letters differ $(P<.05)$ by Tukey test.

O maior consumo de ração contendo 15\% de PB (Tabela 6) pode ser atribuído ao fato de a quantidade protéica estar abaixo do nível adequado para a espécie, tendo que aumentar sua ingestão para obter o mínimo necessário.

Considerando que os peixes comem primariamente também para cobrir suas necessidades de energia (Forbes, 1995), a ingestão voluntária de alimento pode ser influenciada pela quantidade de energia na dieta. Porém, as rações experimentais utilizadas no presente experimento eram isoenergéticas, podendo-se inferir que as respostas dos peixes tenham sido condicionadas pelo conteúdo protéico das mesmas.

O delineamento experimental empregado permitiu que os peixes de cada aquário fossem submetidos a todos os tratamentos, porém impostos em momentos distintos. Os animais responderam de modo semelhante para todos os tratamentos, sugerindo de que não houve interferência de uma fase sobre a subseqüente em relação ao consumo das rações.

Embora a ração peletizada não seja recomendada por Kubitza (1999) por permanecer no substrato e dificultar a identificação do consumo, o uso de alimentadores de demanda no presente experimento reduziu a possibilidade de desperdício.

A utilização de alimentador de demanda pode ter contribuído para o crescimento dos peixes, pois, segundo Schimittou (1993), a tilápia do Nilo aumenta sua taxa de crescimento quando submetida a regime de múltiplas alimentações diárias. Lovell (1995)
Tabela 6 - Consumo total de alimento (g) Table 6 - Total feed intake $(g)$

\begin{tabular}{lc}
\hline $\begin{array}{l}\text { Tratamento } \\
\text { Treatment }\end{array}$ & $\begin{array}{c}\text { Consumo } \\
\text { Feed intake }\end{array}$ \\
\hline A* & $4328,10 \mathrm{ab}$ \\
$\mathrm{B}^{* *}$ & $4245,60 \mathrm{ab}$ \\
C*** & $5097,50 \mathrm{a}$ \\
$\mathrm{D}^{* * * *}$ & $3180,00 \mathrm{~b}$ \\
$\mathrm{CV} \%$ & 23,35 \\
$\mathrm{P}>\mathrm{F}$ & 0,009 \\
\hline
\end{tabular}

Médias na mesma coluna seguidas por letras diferentes diferem significativamente $(P<0,05)$ pelo teste Tukey.

$A=$ um alimentador com ração com $15 \%$ de $\mathrm{PB}$ e outro com ração $40 \%$ PB.

$B=$ semelhante ao tratamento $A$, porém com inversão dos lados. $\mathrm{C}=$ dois alimentadores abastecidos com rações com $15 \%$ de $\mathrm{PB}$. $\mathrm{D}=$ dois alimentadores abastecidos com rações com $40 \%$ de $\mathrm{PB}$. $A=15 \%$ protein diet on one hand and $40 \%$ protein diet on the other hand. $B=$ alike in $A$, therefore with an inversion on both hands.

$C=$ two feeders supplied with $15 \%$ protein diet.

$D=$ two feeders supplied with $40 \%$ protein diet.

Values in the same column followed by different letters differ $(P<.05)$ by Tukey test.

salienta que esta espécie deve ser alimentada com maior freqüência, por possuir estômago pequeno e rudimentar.

O sexo é um dos fatores que afeta o crescimento dos animais, porém os resultados obtidos não devem ser atribuídos a esta variável, uma vez que foram revertidos sexualmente. Segundo Kubitza (2000), machos revertidos sexualmente possuem maior taxa de crescimento que as fêmeas em um mesmo período e, neste experimento, as tilápias apresentaram crescimento satisfatório (biomassa inicial 13,93g \pm 0,87 g 
e biomassa final 134,58 g $\pm 16,09 \mathrm{~g}$; comprimento inicial $8,80 \mathrm{~cm} \pm 0,47 \mathrm{~cm}$ e comprimento final $18,66 \mathrm{~cm} \pm 0,47 \mathrm{~cm})$.

De acordo com Meriwether (1986), tilápias do Nilo alimentadas com alimentadores de demanda apresentam ganho de peso superior àquelas alimentadas manualmente, corroborando os estudos de Tung \& Shiau (1991) com a mesma espécie.

A possibilidade de existência de competição alimentar entre os peixes com possíveis comportamentos de dominância deve ser discutida. Segundo Volpato et al. (1989), esse comportamento conduz a variações no crescimento entre os peixes dominantes e submissos do grupo, fenômeno descrito como Crescimento Heterogêneo e relacionado ao comportamento territorial da espécie. Por outro lado, Novato (2000) cita que a tilápia do Nilo pode "aprender” a acionar o alimentador de demanda rapidamente e que um primeiro indivíduo condicionado facilita a adaptação do grupo, que se comporta como um cardume, minimizando o estresse e a mortalidade.

Os juvenis de tilápia do Nilo dos tratamentos A e $\mathrm{B}$ ajustaram a quantidade de proteína ingerida para 24\% (Tabela 7).

Os resultados estão de acordo com a teoria de ingestão de alimento voluntário (Page \& Andrews, 1973) e com os dados obtidos por Boujard \& Médalé (1994) sobre a capacidade da truta arco-íris (Oncorhynchus mykiss) em regular a ingestão de alimento, porém, nesse caso, a partir de seu conteúdo energético.

Tabela 7 - Valores médios do ajuste, em porcentagem de proteína bruta dietética, em juvenis de tilápia do Nilo alimentados com rações contendo $15 \%$ e $40 \%$ de PB em sistema de livre escolha

Table 7 - Means values of crude protein feed adjust in Nile tilapia juveniles, feeding with $15 \%$ and $40 \% \mathrm{CP}$ diets in free-choice system

\begin{tabular}{lc}
\hline $\begin{array}{l}\text { Fase } \\
\text { Phase }\end{array}$ & $\begin{array}{c}\text { Proteína ingerida (\%) } \\
\text { Protein intake }\end{array}$ \\
\hline I & 23,98 \\
II & 25,87 \\
III & 24,23 \\
IV & 22,14 \\
Média (Mean) & 24,0 \\
\hline
\end{tabular}

Kentouri et al. (1995) observaram que peixes da espécie Sparus aurata regulam a ingestão das dietas com base nos seus teores de proteína e de energia. Cantelmo et al. (1998) também demonstraram a capacidade de regulação da ingestão dietética a partir do nível protéico da dieta, em matrinchãs (Brycon cephalus).

A relação energia:proteína calculada para a ingestão de $24 \%$ de PB pelos peixes (combinação da ingestão das dietas contendo $15 \%$ de PB e $40 \%$ de PB) neste experimento é de 1:116, valor próximo ao estabelecido como ideal para tilápias - 1:100 (NRC, 1993).

\section{Conclusões}

Juvenis de tilápia do Nilo (Oreochromis niloticus), apresentam habilidade de distinguir e escolher entre rações com diferentes níveis de $\mathrm{PB}$, ajustando a ingestão protéica para, aproximadamente, $24 \%$.

\section{Literatura Citada}

BOUJARD, T.; MÉDALÉ, F. Regulation of voluntary feed intake in juvenile rainbow trout fed by hand or by self-feeders with diets containing two different protein/energy ratios. Aquatic Living Resources, p.211-215, 1994.

CANTELMO, O.A.; RIBEIRO, M.A.R.; NAVARRO, D.G. et al. Capacidade do matrinchã (Brycon cefalus) em regular a ingestão dietética protéica. In: AQÜICULTURA BRASIL'98, Recife. Resumos... Recife: 1998. p.53.

FORBES, J.M. Voluntary food intake and diet selection in farm animals. Wallingford: CAB International, 1995. 531p.

HEPHER, B. Nutrition of pond fishes. Cambridge: Cambridge University Press, 1988. 388p.

KENTOURI, M.; DIVANACH, P.; GEURDEN, I., O. et al. Evidence of adaptative behavior in gilhead sea bream (Sparus aurata) in relation to diet composition, in a self-feeding condition. Ichtyophysiological Acta, v.18, p.125-143, 1995.

KUBITZA, F. Nutrição e alimentação dos peixes cultivados. 3.ed. Jundiaí: KUBITZA, F., 1999. 123p.

KUBITZA, F. Tilápia: tecnologia e planejamento na produção comercial. Jundiaí: KUBITZA, F., 2000. 285p.

LOVELL, R.T. Feeding tilapia. Aquaculture Magazine, v.21. n.3, p.87-91, 1995.

MERIWETHER, F.H. An inexpensive demand feeder for cagereared tilapia. Progressive Fish-Culturist, v.48, n.3, p.226-228, 1986.

NATIONAL RESEARCH COUNCIL - NRC. Nutrients requirements of fish. Washington, D.C.: National Academy Press: 1993. 114p.

NOVATO, P.F.C. Comparação entre os sistemas de alimentação de demanda, manual e automático sobre o desempenho da tilápia vermelha (Oreochromis spp). Jaboticabal: Universidade Estadual Paulista, 2000. 87p. Dissertação (Mestrado) - Universidade Estadual Paulista, 2000. 
PAGE, J.W.; ANDREWS, J.W. Interactions of dietary levels of protein and energy on channel catfish (Ictalurus punctatus). Journal of Nutrition, v.103, n.9, p.1339-1346, 1973.

SCHIMITTOU, H.P. High density fish culture in low volume cages. Singapure: American Soybean Association, 1993. 78p.

STEEL, R.G.D.; TORRIE, J.H.; DICKEY, D.A. Principles and procedures of statistics a biometrical approach. New York: McGraw-Hill, 1997. 666p.

TACON, A.G. Nutrición y alimentación de peces y camarones cultivados. Manual de Capacitacion. Brasília: FAO-ITALIA, 1989. 572p.

TUNG, P.H.; SHIAU, S.Y. Effects os meal frequency on growth performance of hybrid tilapia, Oreochromis niloticus x O. aureus, fed different carbohydrate diets. Aquaculture, v.92, n.4, p.343-350, 1991.
VINATCA, L. Princípios químicos e qualidade da água em aqüicultura: uma revisão para peixes e camarões. Florianópolis: Universidade Federal de Santa Catarina, 1997. 166p.

VOLPATO, G.J.; FRIOLI, P.M.; CARRIERI, M.P. Heterogeneous growth in fishes: some data in the Nile tilapia, Oreochromis niloticus and a general view about the casual mechanisms. Boletim de Fisiologia Animal, v.13, p.7-22, 1989.

Recebido em: 25/07/03

Aceito em: 26/07/04 